\title{
Perempuan Salafi Memaknai Jilbab: Antara Alternatif dan Oposisional
}

\author{
Prima Ayu Rizqi Mahanani* \\ prima.ayu99@yahoo.co.id
}

\begin{abstract}
Abstrak
Jilbab cadar merupakan benda yang menjadi penanda perempuan dari manhaj Salafi. Kajian dan analisis kritis ini menggali lebih dalam terhadap si pemakai jilbab yaitu perempuan Salafi yang memaknai jilbab cadar sebagai alternatif ataukah oposisional. Perempuan Salafi adalah subkultur yang mengonstruksi identitasnya melalui atribut yang menunjukkan ekspresi kulturalnya yaitu: muka ditutup dengan cadar, kerudung lebar yang menjuntai sebatas selutut, gamis yang tidak ketat, tidak tipis, tidak tembus pandang, tidak bermotif, warna kain cenderung gelap, tidak memakai harum-haruman, tidak mengenakan hiasan-hiasan, tidak menyerupai pakaian laki-laki, dan tidak menyerupai pakaian wanita kafir atau fasik Berdasarkan jawaban ketujuh informan, ditemukan makna oposisional yaitu adanya hasrat atau keinginan untuk menggantikan jilbab atau mengubah jilbab populer yang ditandai dengan misi berdakwah melalui lisan dan maupun tulisan secara bertahap. Makna oposisionalnya adalah tuntutan lingkungan yang banyak fitnah dan kerusakan seperti sekarang ini dirasa tidak lagi kondusif untuk menundukkan pandangan selain dengan jilbab cadar yang dianggap lebih utama.
\end{abstract}

Kata Kunci: alternatif, jilbab, makna, oposisional, salafi

\section{Abstract}

Hijab veil is a material which is a marker of the methodology Salafi women. Research and analysis is critical to dig deep against the wearer's head scarf that women who interpret the Salafi hijab veil as an alternative or oppositional. Women Salafi is a subculture that constructs its identity through attribute expression cultural namely: face covered with a veil, the veil width dangling limited to knee, the robe is not strict, not thin, opaque, not patterned, fabric colors tend to be dark, not wearing fragrance -haruman, no decorations, do not resemble men's clothing, women's clothing and did not resemble the infidels or wicked. Based on the answers to seven informants, oppositional meanings found that their intention or desire to replace the popular hijab headscarf or change marked by the mission and preaching through oral and written gradually. Oposisionalnya meaning is that many environmental claims defamation and damage, as now it is no longer conducive to lower his gaze beyond the veil that veils were considered more important.

Keywords: alternative, hijab, meaning, oppositional, salafi

\section{Pendahuluan}

Jilbab sebagai fenomena sosial tidak sekedar simbol dan identitas. Di Indonesia, perdebatan tentang jilbab dimulai saat rezim Soeharto berkuasa. Jilbab

* Korespondensi : Prima Ayu Rizqi Mahanani, Program Studi Komunikasi dan Penyiaran Islam, Jurusan Ushuluddin dan Ilmu Sosial STAIN Kediri. Alamat: Jl. Sunan Ampel No. 7 Ngronggo Kediri 64127. HP: 0817250841. 
menjadi arena pertarungan oleh institusi agama, media, industri, negara, masyarakat, dan orang yang memakai jilbab itu sendiri. Jilbab hingga sekarang masih menjadi tegangan dan negosiasi dari berbagai pihak. Menjadi korpus yang menarik untuk dikaji lebih mendalam.

Jilbab sebagai suatu konsep tidak muncul secara tiba-tiba atau taken for granted. Jejak kata jilbab bisa kita telusuri dari Alquran surat al-Ahzab ayat 59 yang artinya adalah "Hai Nabi, katakanlah kepada isteri-isterimu, anak-anak perempuanmu dan isteri-isteri orang mukmin: "Hendaklah mereka mengulurkan jilbabnya ke seluruh tubuh mereka". Yang demikian itu supaya mereka lebih mudah untuk dikenal, karena itu mereka tidak diganggu. Dan Alloh adalah Maha Pengampun lagi Maha Penyayang". Dari terjemahan ayat tersebut diketahui bahwa istilah jilbab muncul sejak jaman Nabi Muhammad saw yang membawa risalah Islam. Jilbab menjadi tanda pengenal atau identitas umat Islam yang membedakan dengan umat-umat lainnya di luar Islam.

Menurut tafsir Jalalain Perkata, jilbab adalah sejenis baju kurung yang lebar dan dapat menutupi kepala, wajah dan dada (Damas et al., 2013:427). Dari riwayat ini dapat dipahami bahwa jilbab adalah baju atau pakaian yang mengarah pada fesyen. Menurut Malcolm Barnard, arti asli fesyen adalah sesuatu kegiatan yang dilakukan seseorang yang sekarang terjadi penyempitan makna yaitu sebagai sesuatu yang dikenakan seseorang, khususnya pakaian beserta aksesorisnya (www.wikipedia.org).

Kess van Dijk dan Jean Gelman Taylor dalam bukunya Idi Subandy Ibrahim (2011:x) mengatakan bahwa busana (pakaian) merupakan sebuah tanda yang merepresentasikan identitas pemakainya. Dari pendapat ini dapat dipahami bahwa jilbab adalah adalah penanda dari suatu kelompok status tertentu yang mengacu pada ekspresi individualitasnya. Kelompok status ini ditandai dengan gaya hidup tertentu yang menjadi penanda kelompok status tersebut. Dalam penelitian ini mengambil lokus komunitas perempuan Salafi dengan jilbab cadarnya.

Jilbab cadar adalah sebuah benda atau material yang menjadi penanda dari perempuan Salafi. Sistem penanda yang merujuk pada dirinya sendiri. Ada bendabenda konsumsi (jilbab cadar) yang melekat dalam tubuhnya. Benda tersebut menjadi penanda kelas dan penentu posisi. Ada nilai yang dikonstruksikan atas benda. Orang yang mengonsumsi jilbab cadar akan secara aktif mengonstruksikan makna. Makna 
dibangun dalam hubungan antar tanda. Makna bisa dibangun tapi tidak bisa lepas dari kode kulturalnya.

Analisis kritis ini mencoba menggali lebih dalam terhadap si pemakai jilbab yaitu perempuan Salafi yang memaknai tentang jilbab cadar seperti apa? Menunjukkan pemaknaannya sebagai apa? Melihat relasinya berjalin atau berkelindan? Melihat sesuatu itu apakah saling terkait? Dan tentunya akan dihasilkan resepsi yang berbeda-beda, mulai taat pada rezim agama sampai dengan sesuatu pilihan. Melihat jilbab cadar sebagai medan pertarungan pemaknaan sekaligus pertarungan kuasa dari berbagai agensi atau institusi, beragam praktek penandaan, ideologi, dan kepentingan. Mencoba melihat sensitif terhadap 'pertarungan' tersebut, sehingga berusaha untuk mencatat, memahami, dan menalar pertarungan yang terjadi. Memahami kehidupan perempuan Salafi dari sudut pandang mereka. Fenomena perempuan Salafi dengan jilbab cadarnya yang begitu dekat dalam kehidupan kita sehari-hari tetapi masih asing untuk diakrabi.

\section{Jilbab sebagai Praktik Penandaan}

Raymond Williams yang sejalan dengan Thompson dalam Barker (2015:39) mengartikan budaya sebagai keseluruhan cara hidup (a whole way of life). Hal-hal biasa yang ditemukan dalam keseharian di semua masyarakat dan di setiap pikiran. Budaya adalah 'seni' sekaligus nilai, norma dan benda simbolis kehidupan sehari-hari. Kebudayaan dapat dipahami melalui representasi dan praktik kehidupan sehari-hari. Ini disebut materialisme kutural. Meliputi analisis atas semua bentuk signifikasi di dalam tujuan dan syarat produksi mereka (Barker, 2015:42).

Budaya adalah segala bentuk praktek penandaan (signiffing practicess) sekaligus pemaknaan yang menjadi kerangka kerja dalam culture studies. Praktek signifikasi oleh Stuart Hall diartikan "there is a kind of symbolic work, an activity, a practice, which bas to go on in giving meaning to things and in communicating that meaning to someone else" (www.pratitisindri.blogspot.com). Memahami culture sebagai signifying practices (praktek penandaaan) yang selalu partikular (khusus), kontekstual, dan lokal. Dalam hal ini segala hal bentuk penandaan layak dikaji termasuk jilbab.

Signifying practicess jangan dipahami sebagai reproduksi dari budaya dominan atau reproduksi ideologi yang dominan. Bukan sesuatu yang alamiah dikarenakan 
punya dasar pembenar. Signifying practicess yang satu dengan yang lain bisa bertabrakan atau berubah dan sangat partikular dan kontekstual. Menunjukkan signifying practicess di suatu tempat bisa berbeda sama sekali di tempat lain. Sehingga ruang dan waktu perlu dipertimbangkan yang akan menghasilkan pemahaman tentang jilbab menjadi berbeda-beda. Akan ada pergeseran dalam memaknai jilbab. Praktek-praktek ideologi dalam sebuah komunitas, contohnya di komunitas perempuan Salafi.

Proses-proses produksi makna merupakan praktik signifikasi. Meaning adalah social construction atau makna yang dikonstruksi secara sosial. Dalam hal ini jilbab tidak dimaknai dengan fatwa-fatwa, tapi membaca fenomena sosial dari berbagai sisi. Menempatkan fenomena yang dikaji dalam bingkai spasial dan temporal. Memaknai jilbab sebagai sesuatu yang beragam, contohnya: memaknai jilbab sebagai simbol kesalehan, sebagai kewajiban, sebagai ketaatan, sebagai perlawanan, sebagai bentuk kebijakan, bentuk penyamaran, bentuk ekspresi kemuslimahan untuk membedakan dengan style muslimah lainnnya, sampai pada sebagai komoditi yang membentuk life style. Jadi, ada perbedaan dan pergeseran dalam memaknai jilbab sesuai dengan bingkai ruang dan waktunya.

Ciri khas kajian budaya dan media adalah sensitif pada bentuk-bentuk siasat, bahkan pada level yang sangat mikro atau privat. Mempunyai watak sensitif dengan aspek politik (politically sensitive in any aspect at everyday life in macro and micro level on institution life dan non institution life) dan juga power dalam pengertian yang sangat mikro. Sehingga akan diketahui pada momen mana yang menunjukkan dominan dan berkuasa. Ada rezim-rezim kebenaran (regime of truth) yang lain dan culture studies memperlihatkan rezim-rezim kebenaran yang lain tersebut. Rezim tersebut diantaranya adalah rezim pemaknaan, rezim kuasa, rezim ekonomi, dan lain-lain. Jadi, sudut pandangnya adalah budaya sebagai arena pertarungan kuasa dan relasi-relasi kuasa yang lain, bertarung dan bernego, dan siapa yang dominan dalam ruang waktu tersebut.

Merujuk pendapat Raymond Williams bahwa culture as site of domination and resistance. Ada dominasi dan resistensi yang mewujud pada negosiasi-negosiasi. Budaya sebagai medan pertarungan ideologi dan kuasa. Sebagai medan perjuangan (site of struggle) memberi arti bahwa perjuangan politik melalui budaya yang terinspirasikan Gramsci merupakan revolusi panjang. Ada gerakan sosial baru yang tergetnya tidak 
pada makro tapi individu personal yang mewujud dalam gaya hidup. Jadi, kajian ini berusaha membongkar jilbab cadar sebagai arena pertarungan berbagai makna, kuasa, dominasi, resitensi, agensi, represi, dan negosiasi.

\section{Perempuan Salafi dalam Perspektif Subkultur Dick Hebdige}

Subkultur adalah gejala budaya dalam masyarakat industri maju yang umumnya terbentuk berdasarkan usia dan kelas. Secara simbolis diekspresikan dalam bentuk penciptaan gaya (style) dan bukan hanya merupakan penentangan terhadap hegemoni atau jalan keluar dari suatu ketegangan sosial”. Subkultur lebih jauh menjadi bagian dari ruang bagi penganutnya untuk membentuk identitas yang memberikan otonomi dalam suatu tatanan sosial masyarakat industri yang semakin kaku dan kabur (www.wikipedia.org).

Secara sosiologis, sebuah subkultur adalah sekelompok orang yang memiliki perilaku dan kepercayaan yang berbeda dengan kebudayaan induk mereka. Subkultur dapat terjadi karena perbedaan usia anggotanya, ras, etnisitas, kelas sosial, dan/atau gender, dan dapat pula terjadi karena perbedaan aesthetik, religi, politik, dan seksual; atau kombinasi dari faktor-faktor tersebut. Anggota dari suatu subkultur biasanya menunjukan keanggotaan mereka dengan gaya hidup atau simbol-simbol tertentu. Karenanya, studi subkultur seringkali memasukan studi tentang simbolisme (pakaian, musik dan perilaku anggota sub kebudayaan) dan bagaimana simbol tersebut diinterpretasikan oleh kebudayaan induknya dalam pembelajarannya (www.wikipedia.org).

Secara harfiah, subkultur terdiri dari dua kata. Sub yang berarti bagian, sebagian dan kultur kebiasaan dan pembiasaan. Kata 'sub' mempunyai arti konotasi yang khusus dan perbedaan dari kebudayaan dominan atau mainstream. Kata 'kultur' dalam subkultur menunjuk pada keseluruhan cara hidup yang bisa dimengerti oleh para anggotanya (www.wikipedia.org).

Secara konseptual, subkultur adalah sebuah gerakan atau kegiatan atau kelakuan (kolektif) atau bagian dari kultur yang besar. Yang biasanya digunakan sebagai bentuk perlawanan akan kultur mainstream tersebut. Bisa berupa perlawanan akan apa saja; agama, negara, institusi, musik, gaya hidup dan segala yang dianggap mainstream. Secara kasar itu bisa diartikan juga sebagai 'budaya yang menyimpang'. 
Jika suatu subkultur memiliki sifat yang bertentangan dengan kebudayaan induk, subkultur tersebut dapat dikelompokan sebagai kebudayaan tandingan. Kebanyakan kita menganggap dan mengidentikkan subkultur dengan suatu kegiatan yang sifatnya negatif (www.wikipedia.org).

Subkultur dalam konteks kekinian adalah komunitas Salafi. Memperluas konsep subkultur dengan meneliti perempuan Salafi dengan jilbab cadar. Merupakan bagian dari yang dominan tapi menciptakan sesuatu yang berbeda atau distinct dari yang dominan, sebagai bentuk resistensi, tapi tidak bisa lepas dari yang dominan.

Subkultur bisa diperluas dalam ekspresi keagamaan. Subkultur muncul dari kelas-kelas bawah. Kelompok yang dianggap subordinat tapi punya cara untuk bertahan diri dan resistensi, dengan menunjukkan simbol-simbol subkultur dalam resisten subkultur. Subkultur sebagai bagian dari sekaligus resistensi dari dominant culture dan popular culture

Salafi adalah varian kultural masyarakat muslim yang mengklaim puritan pada ideologi. Komunitas Salafi sebagai aplikasi dari konsep subkulturnya Dick Hebdige. Pemaknaan jilbab bercadar oleh perempuan Salafi merupakan tampilan dari komunitas sub kultur.

Teoretisi dari Dick Hebdige memuat konsep kunci tentang identitas (masa muda sebagai kesenangan, masa muda sebagai masalah) dan resistensi melalui berbagai ritual. Proposisinya adalah representasi-representasi media yang terpolarisasi-pelbagai kontradiksi ideologis dan perilaku generasi muda yang menentang budaya yang dominan (Burton, 2012:136).

Identitas yang dilekatkan pada perempuan Salafi adalah berjilbab cadar. Identitas sosial direkonstruksi dari jejaring makna dan hubungan sosial yang ada di sekitar kita, dan dari hal ini kita belajar memahami diri kita sendri termasuk hubungan kita dengan budaya dominan. Identitas yang merupakan bagian dari suatu subkultur yang dapat dikenali harus memproduksi hubungan yang bersifat perjuangan, jika bukan merupakan benar-benar oposisi terhadap budaya dominan terebut. Mencoba mengabaikan dan menghindari kekuatan-kekuatan koersif arus utama (mainstream) sebisa mungkin (Burton, 2012:160).

Hebdige memberikan kontribusi pada resistensi. Ide 'perlawanan terhadap ritual' tidak asing lagi bagi subkultur. Ritual-ritual bahasa yang menggunakan bahasa 
dan perilaku jelas merupakan tanda identitas, tanda kebebasan. Jadi problematisasinya adalah dengan cara apakah ritual-ritual menjadi mengandung perlawanan, mengandung simbol kotradiksi-kontradiksi ideologis (Burton, 2012:161).

Lefebvre mengatakan ada ekspresi dalam sebuah subkultur. Tanda-tanda yang melekat dalam subkultur menjadi arena perjuangan kelas. Perjuangan antara wacana yang berbeda, definisi yang berbeda dan makna karena ideologi. Perjuangan dalam kepemilikan tanda yang meluas bahkan daerah yang paling biasa dalam kehidupan sehari-hari (Durham, 2006:151). Jean Genet mengatakan dalam subkultur ada pola dasar yang 'tidak wajar' menyimpang, mencontohkan praktek perlawanan melalaui gaya. Subkultur sebagai pelanggaran simbolik dari tatanan sosial, yaitu sebuah gerakan yang menarik dan akan terus menarik perhatian, untuk memprovokasi sebuah kecaman dan untuk bertindak, sebagai pembawa signifikansi fundamental di subkultur (Durham, 2006:152).

Objek kajian dan analisis kritis ini adalah manhaj Salafi yang merupakan subkultur dengan menciptakan ekspresi-ekspresi kulturalnya sendiri sekaligus mengembangkan keunikan-keunikan atau kekhasan yang menabrak dominan. Menciptakan distingsi di antara popular culture yaitu jilbab pada umumnya. Mereka mengonstruksi identitasnya sendiri melalui atribut yang menunjukkan ekspresi kulturalnya, antara lain muka ditutup dengan cadar, kerudung lebar yang menjuntai sebatas selutut, gamis yang tidak ketat, tidak tipis, tidak tembus pandang, tidak bermotif, warna kain cenderung gelap, tidak memakai harum-haruman, tidak mengenakan hiasan-hiasan, tidak menyerupai pakaian laki-laki, dan tidak menyerupai pakaian wanita kafir atau fasik.

Jilbab bercadar yang anti mainstream menjadi basis material kebudayaan yang bisa digali lebih dalam. Adakah politic of different yang menunjukkan mereka itu berbeda dalam memaknai jilbab. Dalam hal ini pengguna jilbab bukan pengguna pasif, mereka bisa memaknai jilbab yang dipakainya ketika menyampaikan pendapatnya tentang jilbab. Perempuan Salafi yang menjadi infoman saya bisa diidentifikasikan menurut usia, status, latar belakang keagamaan, dan profesi.

\section{Makna Jilbab: Alternatif ataukah Oposisional?}


Mulai pertengahan 1980-an, berbusana muslimah dilihat tidak lagi cukup hanya dengan menutup kepala dengan selendang seperti layaknya masa-masa sebelumnya. Menutup rapat seluruh bagian tubuh yang dianggap aurat dipandang sebagai cara yang lebih pas. Bagian tubuh yang dapat diperlihatkan ditempat umum hanyalah wajah, telapak tangan, dan kaki.

Meskipun begitu, pakaian tetaplah memiliki fungsi sosial sebagai alat komunikasi dan ekspresi pemakainya. Karena itu, tidak mengherankan bila busana muslimah pun terus mencari bentuk-bentuk baru. Modernitas alternatif yang diperlihatkan melalui fenomena jilbab di Indonesia dipandang disertai oleh kesadaran religius. Dalam buku Suzanne Brenner yang berjudul "Reconstructing Self and Society: Javanese Moslem Women and 'the Veil' menceritakan fenomena "Islamisasi" dalam berbusana. Karenanya bila jilbab dilihat sebagai lambang dari gerakan Islam secara luas, hal itu mencerminkan pola fikir dan kesadaran historis yang modern (Ibrahim, 2011: 275).

Berbicara tentang pakaian sesungguhnya berbicara tentang sesuatu yang sangat erat dengan diri kita. Seperti dalam kata-kata Thomas Carlyle, pakaian menjadi "perlambang jiwa" (emblems of the soul). Pakaian bisa menunjukkan siapa pemakainya. Dari Eco, "I speak through my clothes" (aku berbicara lewat pakaianku). Pakaian yang kita kenakan membuat pernyataan tentang diri kita (Ibrahim, 2011: 266).

Dalam buku fashion as communication karya Malcom Barnard bahwa memahami fungsi retoris fashion untuk menentukan tempat dan ruang gerak fashion dalam membentuk dan memelihara peran, aktual, ritual, dan tanggung jawab budaya. Diperlukan pandangan yang elegan untuk membawa kita pada pemahaman yang lebih dalam tentang peran dan makna busana atau pakaian bagi pemakai dan orang yang memandangnya (Barnard, 2011:vi).

Basis-basis material kebudayaan menurut Raymond Williams adalah produkproduk benda materialnya. Poin pokok pendapat Williams bahwa culture punya potensi sebagai the rulling ideas juga resistensi. Jadi membantu kita lebih sensitif membaca pertarungan makna dalam ekspresif-ekspresif kultural dan kultur-kultur yang resisten. Konsep lain dari Williams adalah kapan alternatif dan kapan oposisional. 
Alternatif adalah gaya hidup yang lain dari yang lain yang dimaksudkan sebagai cara yang tidak mengubah yang dominan, ingin diakui beda. Oposisional adalah bukan sekedar ingin diakui beda tapi ingin mengubah yang dominan itu dalam perspektif yang oposisional. Pemaknaan jilbab cadarnya itu alternatif ataukah oposisional? Diteliti apakah sekedar gaya atau agenda bahwa muslimah ditampilkan seperti itu. Ada moment kapan oposisi dan kapan alternatif.

Ketujuh informan yang berhasil diwawancarai antara lain: 1) Y berusia 23 tahun, belum menikah, guru, bercadar sejak 2014, 2) A berusia 26 tahun, menikah, berjualan on line, bercadar sejak 2010, 3) R berusia 28 tahun, menikah, ustadzah, bercadar sejak 2007, 4) Ai berusia 27 tahun, menikah, berjualan online, bercadar sejak 2014, 5) D berusia 28 tahun, menikah, berjualan online, bercadar sejak 2007, 6) Rk berusia 30 tahun, menikah, berjualan online, bercadar sejak 2006, 7) F berusia 30 tahun, menikah, ibu rumah tangga, bercadar sejak 2008. Dari ketujuh perempuan salafi tersebut semuanya memaknai jilbab bercadar sebagai bentuk ketaatan kepada sang pencipta. Pertarungan makna yang disebabkan oleh rezim agama.

Dari penjelasan informan $\mathrm{Y}$ dan $\mathrm{R}$ didapatkan pemahaman tentang Salafi yaitu sebutan bagi yang menyandarkan pemahaman beragamanya dengan pemahaman para salafush sholih. Mereka adalah tiga generasi setelah Rasulullah yakni sahabat, tabi'in (muridnya sahabat) dan tabi'ut tabi'in (muridnya tabi'in). Mengapa kita menyandarkan pemahaman sesuai pemahaman mereka? Sebab sepeninggal Rasulullah terdapat banyak kelompok dengan pemahamannya masing-masing. Terutama setelah generasi tabi'ut tabi'in, maka sebagai muslim sudah selayaknya kita mengambil pedoman sesuai dengan pemahaman Alquran dan Assunnah saja, dan in sya Alloh pemahaman yang tepat adalah pemahaman salafush sholih tersbut yang in sya Alloh masih pure sesuai dengan Alquran dan Assunnah. Yang kemudian mereka ini diistilahkan dalam syariat sebagai kaum salaf, maka secara istilah pula kaum muslim yang beramal sesuai dengan apa yag mereka (kaum salaf) contohkan ialah yang disebut muslim Salafi. Dari sini jelaslah, bahwa Salafi bukan merupakan kelompok, melainkan suatu pemahaman dalam ber-Islam. Salafi bukan organisasi tapi manhaj atau metode ber-Islam. Tidak ada organisasi, kapan didirikannya, tidak ada ketua atau presidennya, dan sebagainya, yang mana pemahaman ini sepatutnya diikuti oleh setiap muslim. 
Relasi yang terjadi adalah karena ideologi sehingga mereka terhegemoni. Ideologis adalah semesta realitas yang tidak tertata kemudian menjadi terpahami ketika kita menemukan jawabannya, membuat semesta realitas yang tidak tertata menjadi terpahami. Ideologi ada pada level gagasan. Jadi satu gagasan yang membuat kita menjadi sensible (terpahami) dan diterima menjadi sesuatu yang alamiah (ideologi).

Seperti yang disampaikan Y bahwa jilbab beserta cadar adalah cara mereka untuk taat kepada Alloh, mengikuti apa yang telah Alloh perintahkan di Alquran dengan mencontoh sebaik-baik penuntun yakni Rasulullah salallaahu 'alaihi wasalam. Jilbab dan cadar yang merupakan perintah dari Alloh ini juga sekaligus cara bagi kami untuk menghormati diri kami sendiri. Sebab setiap wanita, Alloh ciptakan dengan keindahan, dan keindahan wanita terlalu berharga untuk dibagi pada setiap mata". Informan A mengatakan bahwa sebagai seorang muslimah wajib taat kepada Alloh dan Rasul-NYA. Salah satu bentuk ketaatan tersebut adalah menutup aurat dengan sempurna ketika berada di luar rumah dan atau bertemu dengan orang yang tidak halal melihat auratnya.

Penjelasan lengkap disampaikan oleh $\mathrm{R}$, bahwa makna jilbab cadar bagi perempuan muslimah pada dasarnya berpakaian merupakan ibadah, di mana suatu ibadah hanya akan diterima oleh Alloh dengan dua syarat: a) Ikhlas melakukan amalan tersebut hanya untuk Alloh, sebagaimana yang tersebut dalam hadits Ahad dari sahabat nabi, Umar radhiyallaahu'anhu bahwa sesungguhnya suatu perbuatan itu tergantung niatnya, bilamana ia niatkan untuk Alloh dan Rosulnya maka ia hijrah kepada Alloh dan Rasul-NYA. Perkara niat ini sangatlah penting, dimana para ulama seperti Asy Syaikh Al 'Utsa, b) Mengikuti Rasulullah, dalam hadits kelima dalam kitab Al Arba'in an Nawawi dari Ummul Mu-minin 'Aisyah radiyallahu'anha" mengatakan bahwa Rosulullah bersabda barangsiapa yang beramal dengan suatu amalan yang tidak pernah dicontohkan dari kami, maka amalan tersebut tertolak.

Dalam beribadah seorang muslim tidak perlu berinovasi dengan berbagai ragam kegiatan ibadah baru, karena bila hal itu dilakukan maka hilanglah hikmah diutusnya Rosul kepada umat, dan agama Islam ini menjadi tidak ada batasanbatasannya, karena setiap orang akan memiliki pandangan yang berbeda-beda. Adapun berhijab merupakan ibadah yang harus dilakuakan dengan menggandeng kedua syarat tersebut, yang juga didalamnya mengandung makna tauhid Uluhiyyah, 
yaitu meniatkannya hanya untuk Alloh semata, dan juga mengandung makna tauhid Rububiyyah, yaitu berhijab dengan mengikuti aturan-aturan Alloh yang maha mengatur alam semesta ini, termasuk manusia didalamnya. Beginilah Rosulullah, sahabat-sahabat nabi, tabii'in, taabi'ut tabii'in melakukan suatu amalan yang dibangun di atas ketauhidan kepada Alloh semata disetiap amalannya.

Selanjutnya informan Ai mengatakan bahwa makna jilbab cadar adalah hijab yang harus dipakai karena itu bentuk ketaatan kepada Alloh dan Rasulnya. Tapi yang dimaksudkan di sini bukan jilbab cadar. Ai lebih menyukai istilah hijab saja. Karena tidak semua yang berhijab itu bercadar dan masih ada perselisihan di antara para ulama dalam menyikapi cadar. Wanita yang tidak berhijab adalah sebagai bentuk maksiat terang-terangan sebagaimana firman Alloh di surat Al Ahzab ayat 36. Hijab juga memberi rasa aman dan pintu fitnah akan berkurang. Ini juga tertuang di surat $\mathrm{Al}$ Ahzab ayat 59. Sedang tidak berhijab mengundang fitnah. Hijab yang membalut tubuh wanita akan mampu meredam gejolak syahwat kaum laki-laki, adapun wanita yang memamerkan bentuk tubuh dan perhiasannya dihadapan kaum laki-laki bukan mahram hanya akan mengundang perhatian laki-laki hidung belang dan serigala berbulu domba. Sehingga seseorang dianjurkan menundukkan pandangan demi menjaga fitnah sebagaimn firman Alloh di surat An Nur ayat 30.

Informan D menjelaskan bahwa makna jilbab secara umum adalah kewajiban muslimah yang mana hal itu disebutkan dalam surat Al Ahzab ayat 59, surat An Nur 31, dan hadits-hadits nabi lainnya". Sedangkan informan Rk mengatakan makna jilbab adalah makna melaksanakan perintah Alloh untuk menutup diri dari pandangan laki-laki bukan mahram. Selanjutnya informan F menyampaikan jilbab dan cadar adalah identitas seorang muslimah. Dengan berjilbab seorang perempuan bisa diketahui bahwa dia adalah seorang yang beragama Islam walaupun kita tidak mengenalnya sama sekali”.

Dikatakan alternatif karena adanya pengakuan informan bahwa perempuan Salafi dengan jilbab cadar adalah ingin menunjukkan mereka berbeda. Makna alternatif ketika mereka meresepsi jilbab cadar sebagai salah satu identitas wanita muslimah karena Alloh lah yang menetapkan peraturan tersebut, sebagai cara beragama mereka yang ingin mendapat ridho Alloh, sebagai kewajiban bagi wanita muslimah, dan salah satu cara untuk beribadah kepada Alloh yang telah dicontohkan 
oleh isteri-isteri Rasulullah dan para sahabiyah. Untuk mendapat keutamaan atau pahala menjalankan sunnah sahabiyah dan untuk menjaga kehormatan diri.

Dari wawancara yang telah dilakukan, mereka memaknai alternatif ketika menghukumi jilbab bercadar secara sunnah. Terdapat dua fatwa mengenai cadar yaitu sunnah dan wajib. Bagi yang mengambil pendapat bahwa cadar adalah sunnah maka cadar bukan keharusan, dalam artian cadar boleh dipakai dan boleh juga dilepas, sekalipun didepan laki-laki yang non mahrom. Apabila mengambil fatwa wajib, maka cadar merupakan keharusan. Bercadar bukan menjadi keharusan ketika berada dalam kondisi yang tidak memungkinkan untuk bercadar. Misalnya, karena lingkungan yang menganggap aneh, apabila ada keluarga yang menentang, ataupun belum siap karena belum terbiasa. Intinya tidak ada paksaan dalam agama ini untuk bercadar. Walaupun ada perselisihan di antara ulama tentang wajib tidaknya bercadar, namun tidak ada ulama yang melarangnya

Berdasarkan jawaban ketujuh informan, ditemukan makna oposisional yaitu adanya hasrat atau keinginan untuk menggantikan jilbab atau mengubah jilbab populer yang ditandai dengan misi berdakwah melalui lisan dan maupun tulisan secara bertahap. Intinya berbagi ilmu dan mendoakan agar mereka yang belum berjilbab sesuai syariat mendapat petunjuk dan hidayah untuk memakai. Selebihnya tentunya tergantung orang yang bersangkutan ingin mencari hidayah atau tidak dan tergantung Alloh tentunya yang memberikan hidayah atau tidak. Jadi melalui misi berdakwah untuk merangkul yang lain agar berjilbab cadar yang dimulai dari keluarga terdekat terlebih dahulu. Perlawananan terhadap jibab yang tidak sesuai syariat dilakukan dengan tetap semangat dan terus berdakwah.

Indikator oposisionalnya yaitu karena tuntutan lingkungan yang sudah tidak lagi kondusif untuk menundukkan pandangan selain dengan jilbab bercadar. Apalagi di zaman yang banyak fitnah dan kerusakan seperti sekarang ini, maka memakai cadar adalah lebih utama. Karena banyaknya pemahaman yang keliru dengan mengartikan berpakaian sesuai syariat adalah budaya. Menutup aurat dengan jilbab bercadar tidak sama dengan pakaian jeans yang biasa dalam budaya Indonesia modern atau Amerika dan Eropa. Berpakaian yang berarti budaya misalnya koteka di Papua atau di Banjar dengan budaya berpakaian berwarna kuning. Jadi, cara berpakaian sesuai syariat tidak bisa dikategorikan sebagai budaya. Kedua hal tersebut 
jelas-jelas tidak sama. Berjilbab sesuai syariat merupakan perintah Tuhan sedangkan berbusana daerah atau berpakaian modern adalah buatan manusia.

Mengenakan cadar yang dilakukan setelah turunnya ayat jilbab, bisa kita katakan bahwa cadar bukanlah merupakan budaya Arab. Dikisahkan dalam suatu hadits shohih saat turun perintah agar wanita berhijab, maka seketika itu juga wanitawanita di zaman Rasulullah yang telah beriman kepada Islam langsung menutupkan tubuh-tubuh mereka, sampai hanya terlihat matanya saja. Maka bila hijab bercadar merupakan sebuah budaya saat itu tentu tidak perlulah mereka bersikap demikian.

\section{Kesimpulan}

Fashion sebagai site of resistant dan dominant. Menjadi media tarik ulur antara dominasi dan negosiasi. Dasar kecurigaannya adalah jangan-jangan itu merupakan praktek kuasa dan dominasi tertentu. Menjelaskan sebuah ideology dan power beroperasi dalam komunitas tersebut. Sehingga perspektif Dick Hebdige tentang subkultur cocok untuk membahas manhaj Salafi ini. Subkultur yang merupakan bagian dari kultur dominan menunjukkan sikap alternatif dan oposisional. Subkultur ini dengan sengaja mengadopsi kultur dominan lalu mengapropriasinya sehingga bisa bermakna alternatif ataukah oposisional yang bersifat subversif.

Sebuah komunitas akan menetapkan identitas dan kulturnya sendiri-sendiri. Meskipun mereka tidak mau disebut kelompok ataupun organisasi, melainkan suatu metode ber-Islam. Ada kekuasaan beroperasi dalam diri perempuan Salafi, hingga dalam menyampaikan resepsinya terhadap makna jilbab cadar mengarah pada praktik pemaknaan yang judgemental yaitu benar dan tidak benar, pantas dan tidak pantas yang menghasilkan fatwa-fatwa. Ada upaya menstabilkan makna (ideologi) dan mereka amini dengan spontan dan sukarela yang melahirkan hegemoni.

Dari ketujuh perempuan salafi tersebut semuanya memaknai jilbab cadar sebagai bentuk ketaatan kepada sang pencipta. Ada relasi ideologi yang disebabkan oleh rezim agama. Ada makna alternatif dan makna oposisional dalam memaknai jilbab cadar yang keduanya berjalan beriringan tergantung konteks, situasi, kondisi, spasial dan temporal. 


\section{Daftar Pustaka}

Barker, Chris. 2015. Cultural Studies; Teori \& Praktik. Yogyakarta. Kreasi Wacana.

Barnard, Malcolm. 2011. Fashion sebagai Komunikasi. Yogyakarta. Jalasutra.

Burton, Graeme. 2012. Media dan Budaya Populer. Yogyakarta. Jalasutra.

Damas, Taufiq et al. 2013. Alquran, Tafsir Jalalain Perkata. Jakarta. PT. Suara Agung.

Durkheim, Meenakshi Gigi and Douglas M. Kellner (eds.). 2006. Media and Cultural Studies: Keyworks. Blackwell Publishing.

Ibrahim, Idi Subandy. 2011. Budaya Populer sebagai Komunikasi. Yogyakarta. Jalasutra.

Signiffing Practicess/http://www.pratitisindri.blogspot.com. Akses: 7 Januari 2016 (01:11:08 WIB)

Sosiologi Budaya-understanding culture in daily life/http://www.wikipedia.org. Akses: 5 Januari 2016 (10:14:23 WIB) 